\title{
NGF and Excitatory Neurotransmitters Regulate Survival and Morphogenesis of Cultured Cerebellar Purkinje Cells
}

\author{
Susana Cohen-Cory, ${ }^{1,2}$ Cheryl F. Dreyfus, ${ }^{2, a}$ and Ira B. Black ${ }^{2, a}$ \\ 'Laboratory of Neurobiology, The Rockefeller University, and ²Division of Developmental Neurology, Cornell University \\ Medical College, New York, New York 10021
}

The development of cerebellar Purkinje cells is subject to regulation by multiple epigenetic signals. To define mechanisms by which trophic and presynaptic stimulation may potentially regulate Purkinje cell ontogeny, we studied the effects of NGF and excitatory transmitters on Purkinje cell survival and morphological maturation in dissociated cell culture. Purkinje cells were identified by expression of vitamin D-dependent calcium-binding protein and by their characteristic morphology. NGF receptors were selectively localized to Purkinje cells by both ligand and monoclonal antibody binding, suggesting responsivity to the trophic agent. Simultaneous exposure to depolarizing agents and NGF specifically enhanced Purkinje cell survival in culture. NGF, in combination with either high potassium or veratridine markedly increased survival of Purkinje cells. Furthermore, NGF together with the excitatory neurotransmitters aspartate or glutamate promoted a 2-fold increase in survival. In addition, NGF increased Purkinje cell size and promoted neurite elaboration. These effects required simultaneous exposure to NGF and either aspartate, glutamate, or pharmacologic depolarizing agents. Effects on survival or neurite elaboration were not evoked by exposure to trophic factors or transmitters alone. Our results suggest a novel mechanism for regulation of development, in which trophic factor and afferent stimulation interact to promote survival and morphogenesis of developing Purkinje cells.

Increasing evidence suggests that NGF plays an important role in the CNS (for review, see Thoenen et al., 1987; Whittemore and Seiger, 1987; Dreyfus, 1989). While initial studies indicated that basal forebrain cholinergic neurons respond to NGF (Hefti et al., 1984; Martinez et al., 1985), more recent evidence suggests that NGF may have widespread functions in the CNS. The transient expression of NGF receptors (NGF-Rs) in multiple brain areas (Large et al., 1986; Escandón and Chao, 1989; Lu

\footnotetext{
Received May 30, 1990; revised Sept. 14, 1990; accepted Sept. 21, 1990.

We wish to thank Dr. S. Christakos for providing vitamin D-dependent calciumbinding protein antibodies, Dr. P. Bernd for the ${ }^{125} \mathrm{I}-\mathrm{NGF}$, and Dr. E. M. Johnson, Jr., for the NGF receptor antibody used in this study. We also thank Mr. P. Peirce for excellent photography and Ms. E. Vianna for technical assistance. We are most grateful to Dr. T. Wiesel for his valuable suggestions. This work was supported by the Lucille P. Markey Charitable Trust and by NIH Grants NS 10259 and HD 23315. I.B.B. is a recipient of a McKnight Research Project Award.

Correspondence should be addressed to Susana Cohen-Cory, Department of Physiology and Biophysics, College of Medicine, University of California, Irvine, Irvine, CA 92717

a Present address: Department of Neuroscience and Cell Biology, Robert Wood Johnson Medical School, UMDNJ, 675 Hoes Lane, Piscataway, NJ 08854-5635. Copyright (C) 1991 Society for Neuroscience $0270-6474 / 91 / 110462-10 \$ 03.00 / 0$
}

et al., 1989; Allendoerfer et al., 1990) suggest that NGF regulates the ontogeny of diverse neuronal populations.

In particular, previous studies indicate that cerebellar Purkinje cells express NGF-Rs during early development in several species (Eckenstein, 1988; Schatteman et al., 1988; Yan and Johnson, 1988). The selective expression of NGF-Rs by Purkinje cells suggests that NGF may be critical for cerebellar ontogeny. Purkinje cells, the major efferent neurons of the cerebellum, play a central role in the formation of precise cerebellar cortical networks and are critical for integration of motor function. We have previously found that the biologically active, high-affinity NGF-Rs are localized to developing Purkinje cells (Cohen-Cory et al., 1989). The transient expression of NGF-Rs in vivo coincides with the period of active differentiation and synaptogenesis, suggesting that NGF may regulate the ontogeny of this cell type. We have now examined the potential role of NGF during development by studying Purkinje cell survival and differentiation in culture.

Purkinje cells constitute a particularly advantageous model to characterize the role of NGF in brain neuron development: The cellular events that lead to the morphological and functional differentiation of Purkinje cells (Altman, 1972; Altman and Bayer, 1985) and the role that several environmental signals play in cerebellar ontogeny (for review, see Ito, 1984) have been extensively studied. Multiple epigenetic factors are known to regulate Purkinje cell development. For example, afferent innervation is of major importance for differentiation of developing Purkinje cells (Rakic and Sidman, 1973; Berry and Bradley 1976b; Bradley and Berry 1976a,b; Sotelo and ArsenioNunes, 1976). Interactions among several epigenetic signals may be essential for proper regulation of neuronal development (for review, see Purves, 1988). Consequently, we examined the actions of both NGF and putative afferent transmitters in the regulation of Purkinje cell development. Responses to trophic factor and excitatory neurotransmitters were analyzed in dissociated cell culture.

We have found that NGF in combination with the putative excitatory neurotransmitters aspartate and glutamate markedly increased survival and promoted morphological maturation of Purkinje cells.

\section{Materials and Methods}

Tissue dissociation and cell culture. Cerebella from embryonic day 18 (E18) Sprague-Dawley rats were used to establish dissociated cell cultures. Timed pregnant rats were killed by exposure to $\mathrm{CO}_{2}$ vapor. Fetuses were removed by cesarean section and transferred to a sterile petri dish with phosphate-buffered saline (PBS). Fetal cerebella were dissected from surrounding brain tissue. In brief, the skull was removed, and the midbrain was dissected to expose the cerebellum and underlying brain 
stem. Only cerebellar tissue medial to the cerebellar peduncles was dissected, and the meninges were completely removed. Pooled tissue from $2-4$ litters was minced into $0.5-1.0-\mathrm{mm}$ pieces and mechanically dissociated in $2 \mathrm{ml}$ of nutrient medium. Culture conditions were modified after those described previously (Hatten, 1985). Cultures were maintained in nutrient medium containing Minimal Essential Medium (MEM) with Earle's salts supplemented with $2 \mathrm{~mm}$ glutamine (Gibco, Grand Island, NY), glucose $(6 \mathrm{mg} / \mathrm{ml})$, heat inactivated horse serum $(10 \% \mathrm{vol} / \mathrm{vol})$, and low concentrations of penicillin $(0.5 \mathrm{U} / \mathrm{ml})$ and streptomycin $(0.5 \mu \mathrm{g} / \mathrm{ml})$. Cells were counted and plated on poly-Dlysine-coated petri dishes $(35 \mathrm{~mm})$ at a final density of $1 \times 10^{6}$ cells/ dish. Cultures were maintained in nutrient medium at $37^{\circ} \mathrm{C}$ in a $95 \%$ air $/ 5 \% \mathrm{CO}_{2}$ humidified incubator. As indicated, NGF $(200 \mathrm{U} / \mathrm{ml})$, potassium chloride ( $25 \mathrm{mM}$ ), veratridine (VRT; $0.5 \mu \mathrm{M})$, aspartic acid (10 $\mu \mathrm{M})$, and glutamic acid $(10 \mu \mathrm{M})$ were added to the medium at the time of plating. The concentration of the drugs used in this study was determined from dose-response experiments. We chose doses yielding optimal effects without toxicity. The medium was replaced once after 4-5 $\mathrm{d}$ in culture, with the addition of fresh drugs.

Preparation of NGF. The $\beta$ subunit of NGF was prepared from adult mouse salivary glands as previously described (Mobley et al., 1976), and bioactivity was determined following published procedures(Fenton, 1970).

Immunocytochemistry. After $7 \mathrm{~d}$ in culture, dissociates were rinsed in PBS and fixed for $3 \mathrm{hr}$ at $4^{\circ} \mathrm{C}$ in $4 \%$ paraformaldehyde in $0.1 \mathrm{M}$ phosphate buffer (pH, 7.4). Polyclonal antibodies against ncuron-specific enolase (NSE; Polysciences, Inc. Laboratories; 1:1000 dilution) were used for immunostaining the neuronal populations in culture. To detect the Purkinje cell population specifically, a polyclonal antibody to vitamin D-dependent calcium-binding protein (CaBP), generously provided by Dr. S. Christakos, was used at a 1:2000 dilution (Christakos et al., 1987). The 192-IgG monoclonal antibody directed against the rat NGF-R, generously provided by Dr. E. M. Johnson (Yan and Johnson, 1988), was used at a 1:10 dilution. The immunostaining method involved the use of the avidin-biotin complex (ABC) technique (Vectastain $A B C$ kit, Vector Labs.) to visualize staining. Biotinylated secondary antibodies were obtained from Vector Laboratories.

$N G F$ binding assay. The ${ }^{125} \mathrm{I}-\mathrm{NGF}$ binding protocol used in this study has been previously described (Bernd et al., 1988). In brief, E1 8 cerebellar cell cultures were grown for $7 \mathrm{~d}$, nutrient medium was removed, and cultures were washed with 3 changes of MEM with $0.6 \%$ glucose for $2 \mathrm{hr}$ at $37^{\circ} \mathrm{C}$ to remove any endogenous NGF. For ${ }^{125} \mathrm{I}-\mathrm{NGF}$ binding, cultures were incubated with $0.2 \mathrm{nM}{ }^{125} \mathrm{I}-\mathrm{NGF}$ for $1 \mathrm{hr}$ at $37^{\circ} \mathrm{C}$ in MEM, $0.6 \%$ glucose, and $5 \mathrm{mg} / \mathrm{ml}$ bovine serum albumin. Following incubation, cultures were rinsed rapidly 6 times in ice-cold PBS and fixed with $4 \%$ paraformaldehyde. Cultures were immunostained, dipped in L4 emulsion (Ilford), and exposed for autoradiography.

Morphometric analysis and assessment of cell survival. Cultures were examined using a Nikon Labophote 100 microscope. Immunopositive cell counts were obtained by analyzing an area equivalent to $10 \%$ of the dish surface. The number of CaBP-positive cells was expressed as the percent of cells in experimental versus control cultures. Morphometric measurements were performed using representative, isolated $\mathrm{CaBP}$-immunopositive cells in sparse cultures. Cell diameter and ncuritc length were measured with an eyepiece micrometer. Numbers of neurites and branch points per cell were determined by counting. We defined "neurons with spiny processes" as those CaBP-positive cells with processes $0.5-1.0 \mu \mathrm{m}$ in length protruding from central neurites. A drawing tube coupled to the Nikon microscope was used for tracing CaBP-positive cells. An analysis of variance (ANOVA) program was used for the statistical analysis of data.

\section{Results}

To evaluate the potential role of NGF during Purkinje cell ontogeny, we established a culture system allowing analysis of responses to trophic factor stimulation. Dissociated rat cerebellar cell cultures maintained in serum-containing medium fostered survival and differentiation of Purkinje cells. The use of mixed cultures (neuronal and non-neuronal cells) promoted differentiation of Purkinje cells in a relatively rich environment (Fig. 1). This system allowed detailed analysis of the effects of NGF on survival and differentiation of individual neurons. Purkinje cells were visualized immunocytochemically with $\mathrm{CaBP}$ antibodies (Fig. 2). CaBP is a cell-specific antigen exclusively expressed by Purkinje cells within the cerebellum (Jande et al., 1981; Christakos et al., 1987). Phase microscopy confirmed immunopositivity of the entire cell body and processes of CaBPpositive cells in culture. Immunopositive cells appeared as phasebright neuronlike cells, exhibiting morphology characteristic of developing Purkinje cells (Fig. 2).

\section{Purkinje cells in culture express NGF receptors}

While previous studies indicated that Purkinje cells express NGF receptors in vivo, expression in culture had yet to be delineated. In fact, Purkinje cells identified both morphologically and by CaBP immunoreactivity expressed NGF-Rs by immunocytochemical criteria. Using the optimal culture conditions, the antirat NGF-R monoclonal antibody $192-\mathrm{IgG}$ revealed the presence of positive cells that were morphologically identified as developing Purkinje cells (Fig. 3). In all cases examined, NGF-R antigenicity colocalized with $\mathrm{CaBP}$ immunoreactivity (not shown). Expression of NGF-R was confirmed by ${ }^{125}$ I-NGF binding studies. Incubation with radioactive NGF specifically labeled binding sites on CaBP-positive cells (Fig. $4 A$ ). Silver grains were restricted to $\mathrm{CaBP}$-immunopositive cells, suggesting that expression of NGF-R is limited to the Purkinje population. Specific ${ }^{125}$ I-NGF binding was completely abolished in control cultures incubated with 1000-fold excess unlabeled NGF (Fig. $4 B$ ). The cxpression of NGF-Rs by Purkinje cells in culturc suggests that these cells retain the potential ability to respond to NGF in vitro.

\section{NGF and depolarizing stimuli enhance Purkinje cell survival}

Dissociated cell culture allows the study of neuronal survival in a rigorously controlled series of environments. However, normal afferents and cell-cell interactions are disrupted. Because impulse activity apparently regulates Purkinje cell development in vivo, cells were grown under depolarizing conditions, and NGF effects were analyzed. Neuronal cell number was markedly increased in cultures grown for $7 \mathrm{~d}$ in high-potassium medium $(25 \mathrm{~mm} \mathrm{KCl})$. Treatment with high potassium alone increased the cell number by $40 \%$ (Figs. 1, 5). Moreover, NGF significantly increased Purkinje cell number by $75 \%$ over control with no potassium (Fig. 5). However, NGF had no effect in the absence of high potassium. The effect of NGF and potassium in combination was specific and significantly different from that elicited by either agent alone (Fig. 5).

To determine whether depolarization per se was responsible for the potassium-elicited effect, cultures were grown in the presence of veratridine (VRT). The alkaloid depolarizes neurons by opening sodium channels, a mechanism distinct from that of potassium. VRT depolarization increased survival of all neurons, mimicking potassium. VRT treatment alone increased Purkinje cell survival by $130 \%$ (Fig. 6). Moreover, a further and significant $70 \%$ increase in survival was elicited by NGF in the presence of VRT (Fig. 6). Consequently, depolarization with either high potassium or VRT was required for NGF actions on cell survival. These observations raised the possibility that afferent excitatory transmitters and trophic agents act in concert.

\section{NGF and excitatory neurotransmitters enhance Purkinje cell survival}

In the developing rat cerebellum, synaptogenesis largely transpires during the first postnatal weeks, coincident with high NGF-R message expression (Buck et al., 1988; Lu et al., 1989). 

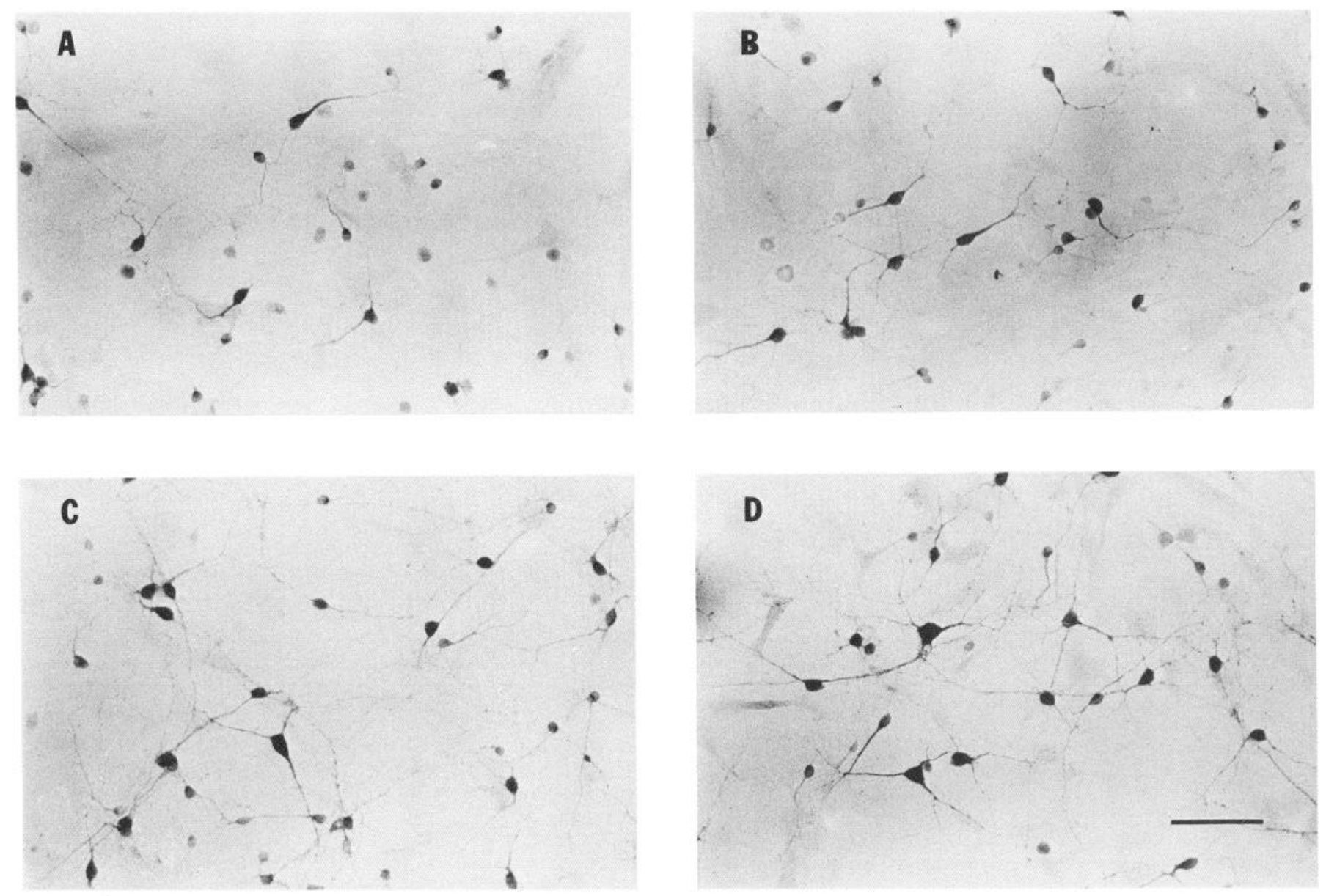

Figure 1. Visualization of neurons in culture by immunocytochemical staining with NSE antibody. Cerebellar cells were grown for $7 \mathrm{~d}$ in culture under standard conditions $(A)$ or in the presence of NGF $(B)$, potassium $(C)$, or potassium with NGF $(D)$. Note the increase in neuronal cell number and neurite length by treatment with potassium or potassium with NGF. Scale bar, $100 \mu \mathrm{m}$.

However, at birth, prior to the establishment of cerebellar excitatory afferent synapses, developing Purkinje cells are already sensitive to L-aspartate and L-glutamate (Woodward et al., 1971; Dupont et al., 1987). To ascertain whether normal innervation is necessary for trophic regulation of Purkinje cell development, we analyzed the role of both aspartate and glutamate on survival. The combination of NGF and either aspartate or glutamate markedly enhanced survival of Purkinje cells (Figs. 7, 8). A specific, $100 \%$ increase in survival was observed after exposure to aspartate and NGF (Fig. 7). A similar effect was obtained with glutamate and NGF (Fig. 8). Unlike effects noted with the pharmacological agents, the specific transmitters L-aspartate and L-glutamate alone had no effect on the survival of CaBP-positive cells (Figs. 7, 8). Moreover, upon exposure to higher doses of glutamate (0.05-1 $\mathrm{mM})$, a toxic effect was observed on all cells (not shown). Consequently, in vivo, excitatory neurotransmitters, in concert with the trophic protein, may regulate Purkinje cell survival.

\section{NGF and depolarizing agents regulate cell size and shape}

To define NGF actions on Purkinje cell development further, we examined the effects of NGF and depolarizing agents on the morphological maturation of cells in culture. Several parameters were evaluated.

\section{Neuritic morphology}

Potassium and NGF. Treatment with potassium alone significantly increased neurite outgrowth in all Purkinje cells (Table 1, Fig. 1). Moreover, treatment with both potassium and NGF elicited specific changes, increasing neurite number per cell (Table 1; cf. control cultures) and neurite branching (Table 1, Fig. 1). In contrast, NGF alone had no significant effect on neurite number or neurite branching. Treatment with NGF and high potassium increased the proportion of cells with spiny neurites (Table 1).

Aspartate/glutamate and NGF. In agreement with the survival results, treatment with aspartate or glutamate had only a moderate effect on neurite morphology. However, treatment with excitatory neurotransmitters and NGF markedly enhanced neuritic length and complexity (Fig. 9). NGF, in combination with aspartate, significantly increased neurite branching (Table 2). The treatment similarly increased the proportion of Purkinje cells with spiny neurites (Table 2).

\section{Cell size}

NGF in combination with high potassium (Table 1), aspartate (Table 2, Fig. 9), or glutamate (Fig. 9), significantly increased the size of the soma of CaBP cells. These effects were not ob- 

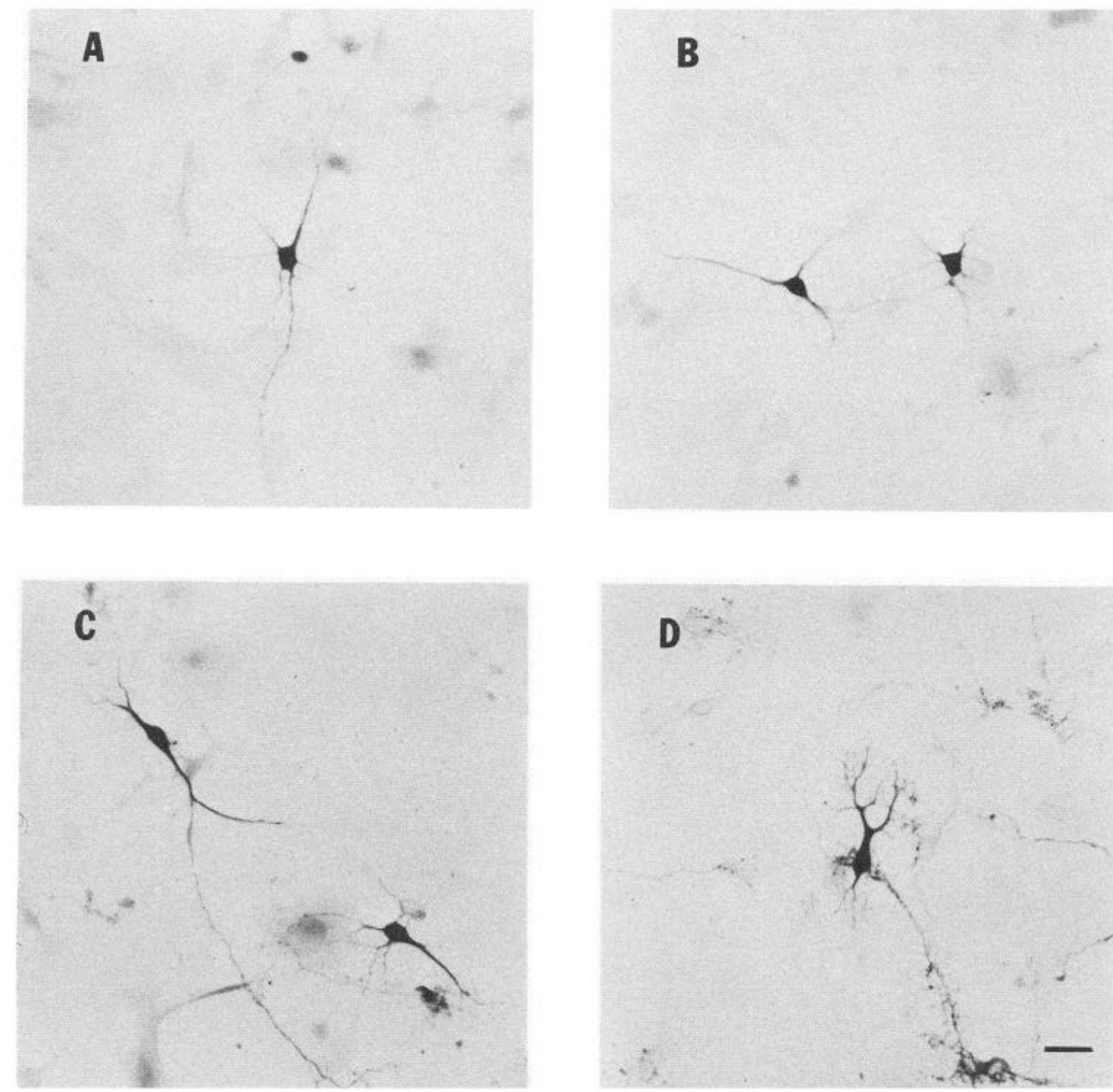

Figure 2. Immunocytochemical visualization of Purkinje cells in culture. Cerebellar cell cultures were grown for $7 \mathrm{~d}$ in the absence $(A)$ or presence of either NGF $(B)$, potassium $(C)$, or potassium with NGF $(D)$ and immunostained with CaBP antibodies. Note the marked enhancement in neurite elaboration by treatment with potassium with NGF. Scale bar, $40 \mu \mathrm{m}$. served by treatment with aspartate, glutamate, or potassium alone.

\section{Discussion}

Localization of the biologically active, high-affinity NGF binding sites to developing Purkinje cells suggested that the factor regulates ontogeny of this specific neuronal population. The present study indicates that NGF and depolarizing signals influence survival and morphological differentiation of Purkinje cells in culture.

\section{A culture system to study Purkinje cell growth}

To begin defining the trophic mechanisms that may regulate Purkinje cell development, we studied NGF in a system readily accessible to experimental manipulation. Dissociated embryonic cell cultures provide a particularly advantageous model, since survival and differentiation of Purkinje cells parallel that observed in vivo. In culture, Purkinje cells develop and express several traits normally present in vivo (see below) and can be visualized immunocytochemically with $\mathrm{CaBP}$ antibodies

Table 1. Effects of potassium and NGF on Purkinje cell size and neurite elaboration

\begin{tabular}{lcccc} 
& Control & NGF & $\mathrm{K}^{+}$ & $\mathrm{K}^{+}+$NGF \\
\hline Cell diameter $(\mu \mathrm{m})$ & $18.5 \pm 0.5$ & $20.4 \pm 0.6$ & $20.9 \pm 0.5$ & $22.4 \pm 0.6^{*}$ \\
Neurite number & $4.5 \pm 0.2$ & $5.6 \pm 0.2$ & $5.6 \pm 0.3$ & $6.3 \pm 0.2^{*}$ \\
Neurite length $(\mu \mathrm{m})$ & $218 \pm 24$ & $339 \pm 36$ & $521 \pm 49^{* *}$ & $592 \pm 40^{* *}$ \\
Branch point number & $3.8 \pm 0.4$ & $5.1 \pm 0.4$ & $5.2 \pm 0.4$ & $7.4 \pm 0.5^{* * *}$ \\
Neurons with spiny processes & $8 \%$ & $30 \%$ & $38 \%$ & $78 \%$
\end{tabular}

E18 rat cerebellar cells were grown in culture and immunostained for CaBP. Fifty cells, in 3 separate dishes prepared on the same day, were analyzed per experimental condition. Doses of $25 \mathrm{~mm} \mathrm{KCl}$ and $200 \mathrm{U} / \mathrm{ml} \mathrm{NGF}$ were used. Statistical analysis was by 1 -way ANOVA and Scheffe $F$ test. Each value represents mean \pm SEM. *, Significantly different from control; ${ }^{* *}$, significantly different from control and NGF; ${ }^{* * *}$, significantly different from control, NGF, and potassium. $p<0.05$. 


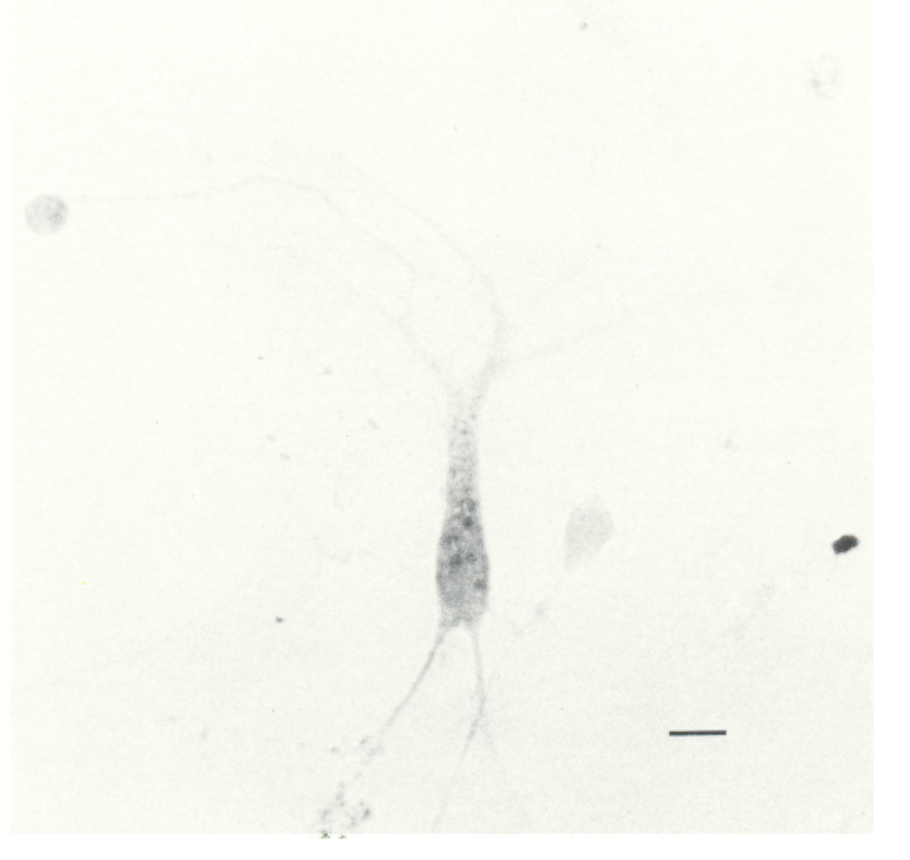

Figure 3. Immunocytochemical visualization of NGF-R-positive cells in culture. Cerebellar cultures were grown for $7 \mathrm{~d}$ in the presence of potassium and NGF and immunostained with the anti-rat 192-IgG antibody. NGF-R-immunopositive cells were recognized as Purkinje cells by morphology and similarity to CaBP-positive cells in sister cultures (not shown). Note the punctate staining over the cell body and developing dendrites. Scale bar, $20 \mu \mathrm{m}$.

(Christakos et al., 1987). However, some of the epigenetic signals known to be important for Purkinje cell development are absent in culture. For example, afferent innervation is known to play a critical role during development, and in cell culture normal circuitry is disrupted. Consequently, we examined the role of afferent neurotransmitters as well as NGF in the regulation of Purkinje cell ontogeny.

During normal cerebellar development, differentiation of Purkinje cells is influenced by 2 distinct afferent systems: the parallel and climbing fibers. In classical studies, Ramón y Cajal provided the first evidence that climbing fibers guide Purkinje dendritic growth (Ramón y Cajal, 1911); subsequent evidence indicated that climbing fibers play an important role in neurite branching (Bradley and Berry 1976a,b; Sotelo and Arsenio-Nunes, 1976). More recently, Mason and Blazeski (1989) have shown that

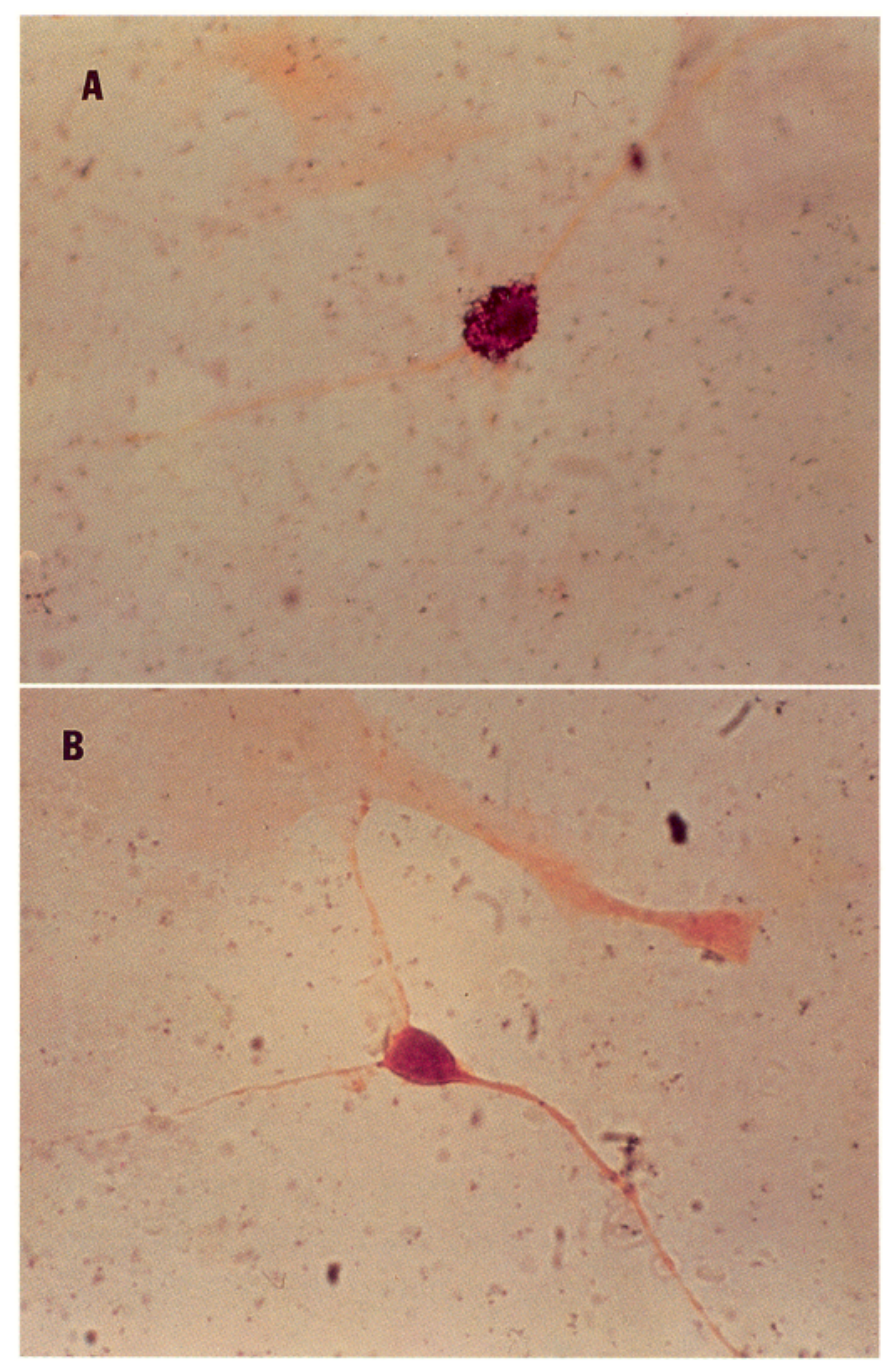

Figure 4. ${ }^{125}$ I-NGF binding to Purkinje cells in culture. ${ }^{125}$ I-NGF binding was identified as silver grains over CaBP-immunopositive cells in culture. $A$, Bright-field illumination reveals the presence of silver grains over an immunoreactive Purkinje cell. $B$, In control cultures exposed to excess unlabeled NGF at the time of incubation with radioactive NGF, only background silver grains were detected. Cell cultures were prepared from E1 8 cerebella and grown for $7 \mathrm{~d}$ in serum-supplemented medium alone. For binding studies, the ${ }^{125}$ I-NGF binding protocol was used (see Materials and Methods); cultures were then fixed and immunostained for $\mathrm{CaBP}$ and treated for autoradiography. The exposure time was $17 \mathrm{~d}$.

Table 2. Effects of aspartate and NGF on Purkinje cell size and neurite branching

\begin{tabular}{lcccc} 
& Control & NGF & ASP & ASP + NGF \\
\hline Cell diameter $(\mu \mathrm{m})$ & $17.6 \pm 0.3$ & $18.1 \pm 0.3$ & $19.1 \pm 0.4$ & $21.0 \pm 0.3^{* *}$ \\
Neurite number & $4.3 \pm 0.1$ & $4.6 \pm 0.1$ & $4.5 \pm 0.2$ & $4.8 \pm 0.2$ \\
Neurite length $(\mu \mathrm{m})$ & $263 \pm 38$ & $302 \pm 36$ & $352 \pm 36$ & $404 \pm 36$ \\
Branch point number & $3.8 \pm 0.4$ & $4.4 \pm 0.3$ & $5.0 \pm 0.4$ & $5.8 \pm 0.3^{*}$ \\
Neurons with spiny processes & $1 \%$ & $2 \%$ & $12 \%$ & $26 \%$
\end{tabular}

E18 rat cerebellar cells were grown in culture and immunostained for CaBP. Fifty cells, in 3 separate dishes prepared on the same day, were analyzed per experimental condition. Doses of $10 \mu \mathrm{M}$ aspartic acid and $200 \mathrm{U} / \mathrm{ml} \mathrm{NGF}$ were used. Statistical analysis was by 1 -way ANOVA and Scheffe $F$ test. Each value represents mean \pm SEM. *, significantly different from control; ${ }^{* *}$, significantly different from control, NGF, and aspartate. $p<0.05$. 


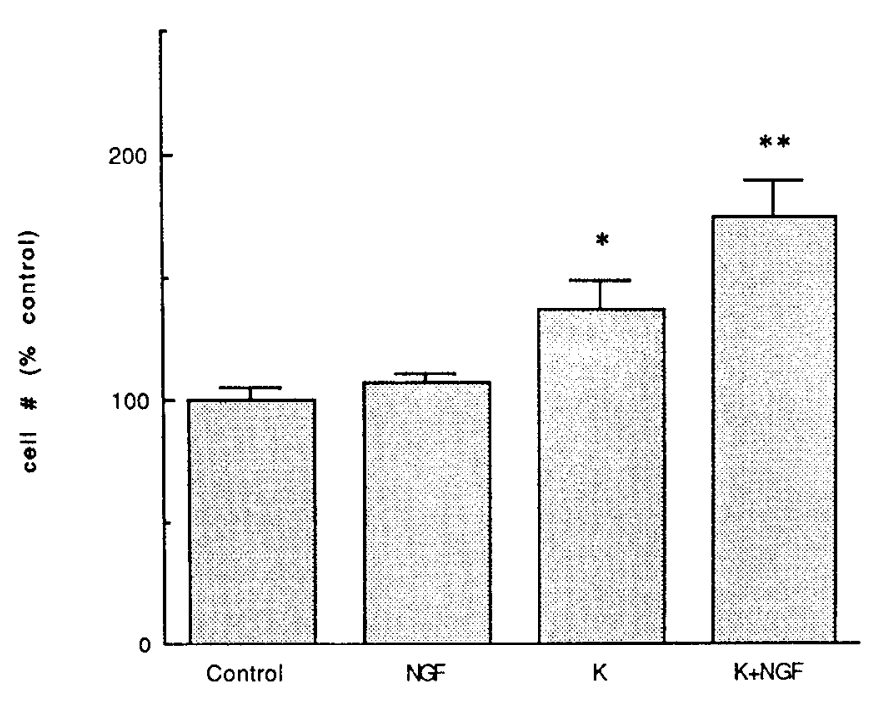

Figure 5. Effects of potassium and NGF on Purkinje cell survival. E18 rat cerebellar cells were grown in culture in the presence or absence of elevated potassium, NGF, or potassium with NGF and immunostained for CaBP. Numbers of positive cells were obtained by analyzing $10 \%$ of the dish area. Triplicates of 4 independent experiments were analyzed per condition. Data is expressed as percent $\mathrm{CaBP}$ cell number compared to controls grown alone. Each experimental value represents mean cell number \pm SEM. Statistical analysis was by 1 -way ANOVA and Scheffe $F$ test. Doses of $25 \mathrm{~mm} \mathrm{KCl}(K)$ and $200 \mathrm{U} / \mathrm{ml} \mathrm{NGF}$ were used. Values depicted are as follows: Control, $100 \pm 4.89 \% ; N G F, 108.25 \pm 4.17 \%$; $K, 137.71 \pm 12.49 \% ; K+N G F, 175.43 \pm 15.44 \%$. The actual number of cells in representative control cultures was $1923.2 \pm 35.21$. $^{*}$, Differs from control and NGF; ${ }^{* *}$, differs from control, NGF, and $\mathrm{K}$ by $p<$ 0.05 .

initial afferent interactions between climbing fibers and undifferentiated Purkinje cells occur during late embryonic stages, prior to dendritic differentiation. During this early stage of cerebellar development, the local expression of NGF message and the expression of NGF receptors by Purkinje cells coincide with the establishment of initial climbing fiber contacts. Consequently, these epigenetic signals may interact during development.

Study of cerebellar mutants (Rakic and Sidman, 1973; Sotelo, 1975; Sadler and Berry, 1989) and of granule cell ablation (Berry and Bradley, 1976a; Crepel et al., 1980) have also indicated that excitatory stimulation by parallel fibers is required for normal maturation of Purkinje cells. Indeed, parallel fiber stimulation coincides with the peak of NGF-R message expression (Buck et al., 1988). Therefore, we examined the interaction of NGF and depolarizing influences in the regulation of Purkinje cell development. Initially, we examined receptor expression in vitro.

\section{Purkinje cells express NGF receptors in culture}

During early development in vivo, Purkinje cells express lowand high-affinity NGF-Rs, suggesting potential responsivity to NGF (Cohen-Cory et al., 1989). We now find that Purkinje cells retained the ability to express NGF-Rs in culture. A highly sensitive ${ }^{125}$ I-NGF binding assay revealed NGF-Rs localized to Purkinje cells in control cultures. Moreover, receptor number was enhanced after treatment with depolarizing agents (see below), allowing the detection of NGF-Rs by monoclonal antibody binding. The selective localization of NGF-Rs to Purkinje cells suggested that receptor expression is specifically limited to this population. In turn, selective expression suggested that Purkinje cells might be responsive to NGF in culture.

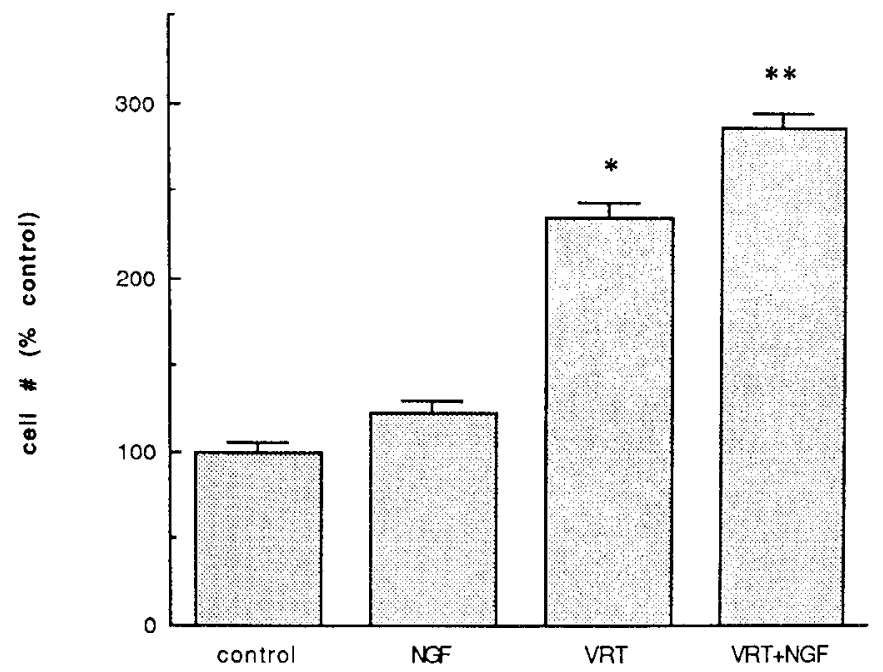

Figure 6. Effects of VRT and NGF on Purkinje cell survival. E18 rat cerebellar cells were grown in culture and immunostained for CaBP. Numbers of positive cells were obtained as described in Figure 5. In this case, duplicates of 4 independent experiments were analyzed per condition. Doses of $0.5 \mu \mathrm{M}$ VRT and $200 \mathrm{U} / \mathrm{ml}$ NGF were used. Values depicted are as follows: Control, $100 \pm 5.42 \% ; N G F, 122.71 \pm 6.29 \%$; $V R T, 234.85 \pm 8.24 \% ; V R T+N G F, 286.85 \pm 8.02 \%$. The actual number of cells in representative control cultures was $1527 \pm 64.17 .{ }^{*}$, Differs from control and NGF; **, differs from control, NGF, and VRT by $p<0.05$.

\section{NGF and pharmacologic depolarizing agents enhance Purkinje cell survival}

The selective expression of NGF-Rs by Purkinje cells in culture led us to analyze the putative effects of NGF on the development of this population. Since presynaptic innervation regulates neuronal differentiation in several systems (Black, 1978), and potentially guides Purkinje cell development, we examined the roles of NGF and depolarizing signals. As an initial approach, we examined the possibility that NGF regulates Purkinje cell survival. In control experiments, Purkinje cell survival declined after 1 week in culture. At this time, only a fraction (10-20\%) of the cells plated survived. Indeed, decreasing survival with time is characteristic of cerebellar macroneurons grown in mixed cultures (Hockberger et al., 1989) and has been associated with a neuronotoxic activity released to the culture medium (GrauWagemans et al., 1984). Treatment with either high potassium or VRT alone increased numbers of all neuronal types, as indicated by an increase in NSE-positive cells (Fig. 1). This result confirmed the well-known effects of depolarizing agents in the promotion of survival of many different populations in culture (Lasher and Zagon, 1972; Nishi and Berg, 1981; Gallo et al., 1987; Hockberger et al., 1987, 1989; Moran and Patel, 1989).

In addition, however, simultaneous exposure to depolarizing agents and NGF specifically increased Purkinje cell numbers in our cultures. NGF, in combination with either high potassium or VRT, selectively increased survival of CaBP-positive neurons, an effect significantly different from the general action of potassium or VRT. Yet, NGF alone did not increase survival of Purkinje cells. The observation that depolarizing signals are required for NGF-induced survival suggests that neuronal depolarization may influence receptivity to the trophic agent. Consequently, afferent innervation in combination with trophic support may govern survival. 


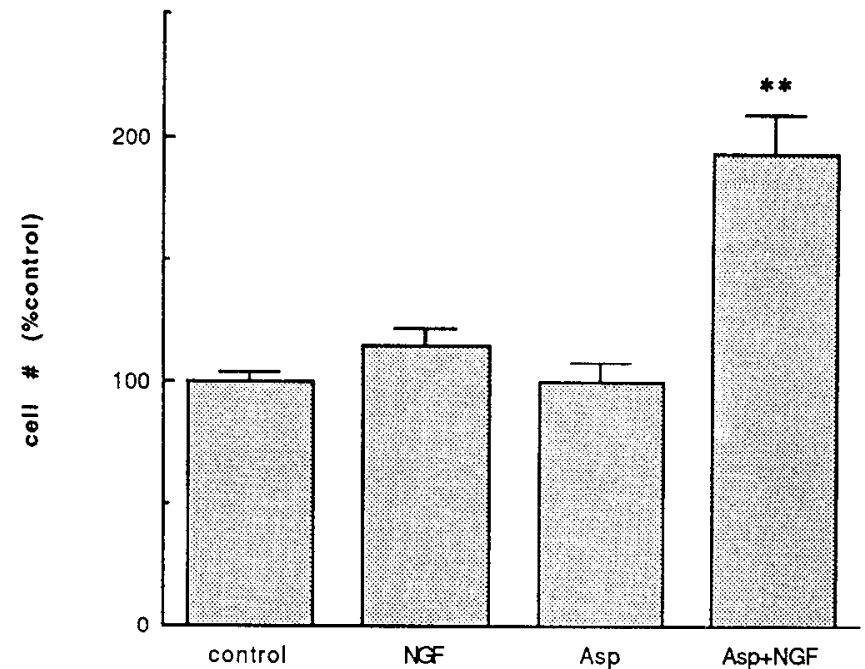

Figure 7. Effects of aspartate and NGF on Purkinje cell survival. E18 rat cerebellar cells were grown in culture, immunostained for $\mathrm{CaBP}$, and analyzed as described for Figure 5 . In this case, duplicates of 2 independent experiments were analyzed per condition. Doses of $10 \mu \mathrm{M}$ aspartate $(A s p)$ and $200 \mathrm{U} / \mathrm{ml}$ NGF were used for the time in culture. Values depicted are as follows: Control, $100 \pm 4.49 \% ; N G F, 115.0 \pm$ $6.72 \%$; Asp, $99.75 \pm 8.42 \% ; A s p+N G F, 194.0 \pm 15.70 \%$. The actual number of cells in representative control cultures was $1688 \pm 99.42$. **, Differs from control, NGF, and aspartate by $p<0.05$.

Although it is apparent from our data that NGF, in combination with depolarizing agents, regulates Purkinje cell survival, 2 other possibilities warrant consideration. First, NGF could act to induce cell proliferation, potentially resulting in increased Purkinje cell number. This is unlikely, however, because Purkinje neurons are postmitotic at the time of dissociation. A second possibility is that NGF could act to induce neuronal differentiation and, therefore, expression of CaBP. While we have not definitively excluded the latter possibility, published results indicate that $\mathrm{CaBP}$ expression is restricted to Purkinje cells in the cerebellum (Christakos et al., 1987). Studies currently in progress are addressing these different mechanisms.

\section{NGF and excitatory neurotransmitters enhance Purkinje cell survival}

Parallel and climbing fibers constitute the 2 major excitatory afferents of Purkinje cells; L-glutamate and L-aspartate are generally regarded as the respective excitatory transmitters. Therefore, we examined the effects of aspartate and glutamate on cell survival. Treatment with aspartate or glutamate, in combination with NGF, markedly enhanced survival of Purkinje cells. Our observation suggests that the combination of excitatory transmitter and NGF is required to enhance survival. Although Purkinje cells are sensitive to excitatory amino acid iontophoresis at the time of dissociation (Woodward et al., 1971; Dupont et al., 1987), the transmitters alone do not alter survival (Hockberger et al., 1989; S. Cohen-Cory, C. F. Dreyfus, and I. B. Black, unpublished observations). Our evidence suggests a novel mechanism in which trophic factors and afferent stimulation interact to promote survival of developing Purkinje cells.

The effects of excitatory neurotransmitters on the survival of Purkinje cells apparently differ from those of the general pharmacologic depolarizing agents. While potassium and VRT alone increased cell survival, aspartate and glutamate elicited effects

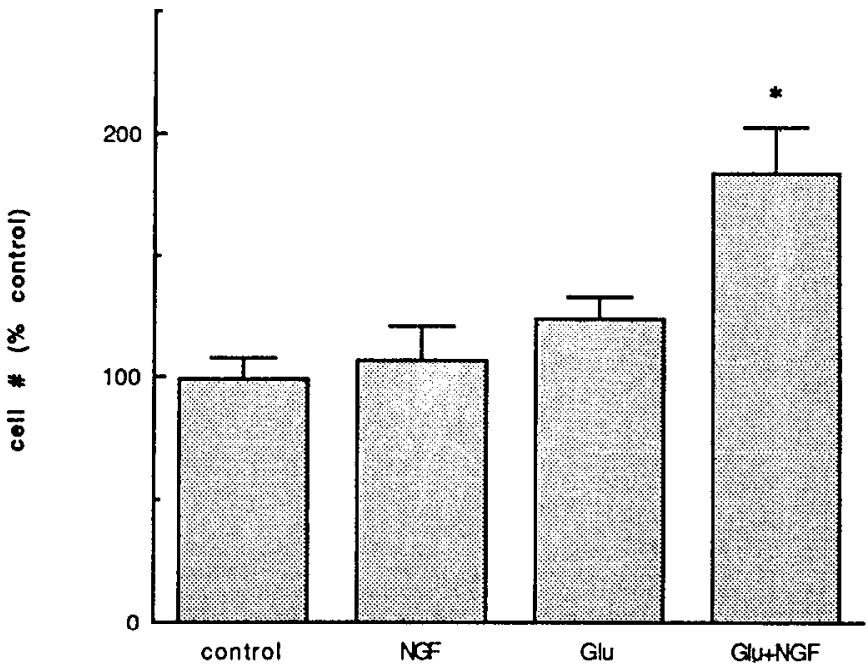

Figure 8. Effects of glutamate and NGF on Purkinje cell survival. E18 rat cerebellar cell cultures were immunostained for $\mathrm{CaBP}$ and analyzed as described for Figure 5. Duplicates of 2 independent experiments were analyzed per condition. Doses of $10 \mu \mathrm{M}$ glutamate $(G l u)$ and $200 \mathrm{U} / \mathrm{ml}$ NGF were used. Values depicted are as follows: Control, $100 \pm 8.96 \%$; $N G F, 107.33 \pm 14.19 \%$; Glu, $124.41 \pm 9.52 \%$; Glu + NGF, $184.23 \pm$ $19.02 \%$. The actual number of cells in representative control cultures was $1691.4 \pm 150.95$. ${ }^{*}$, Differs from control by $p<0.05$.

only in combination with NGF. The fact that naturally occurring transmitters had more restricted effects suggests that these agents act through specific receptors, expressed only by restricted populations in culture. Alternatively, aspartate and glutamate may act through a mechanism distinct from depolarization. A putative role for excitatory neurotransmitters as trophic agents during development remains a possibility.

Differences of effects of pharmacologic depolarizing agents and excitatory neurotransmitters may also be attributable to different mechanisms of action. Elevated potassium is known to act through a more general mechanism to alter survival (Lasher and Zagon, 1972; Kingsbury et al., 1985; Hockberger et al., 1989; Moran and Patel, 1989). Potassium and VRT, consequently, may stimulate multiple neuronal and non-neuronal populations, leading to manifold indirect effects. In contrast, since NGF-Rs are restricted to Purkinje cells (see above), the trophic factor probably acts directly on this specific population.

\section{NGF and excitatory neurotransmitters regulate cell size and shape}

While afferents are known to regulate the morphological differentiation of Purkinje cells (Rakic and Sidman, 1973; Berry and Bradley 1976b; Bradley and Berry, 1976a,b; Sotelo and ArsenioNunes, 1976; for review, see Ito, 1984), underlying mechanisms remain unclear. To define mechanisms by which the 2 epigenetic signals, NGF and innervation, may regulate differentiation, we examined the effects of trophic and excitatory stimulation on morphological maturation.

In fact, NGF increased cell size and promoted neurite elaboration of developing Purkinje cells. The effects required simultaneous exposure to NGF and either aspartate, glutamate, or pharmacologic depolarizing agents. Since only minimal differences in maturation were observed with any agent alone, our results suggest that presynaptic transmitters and NGF act 

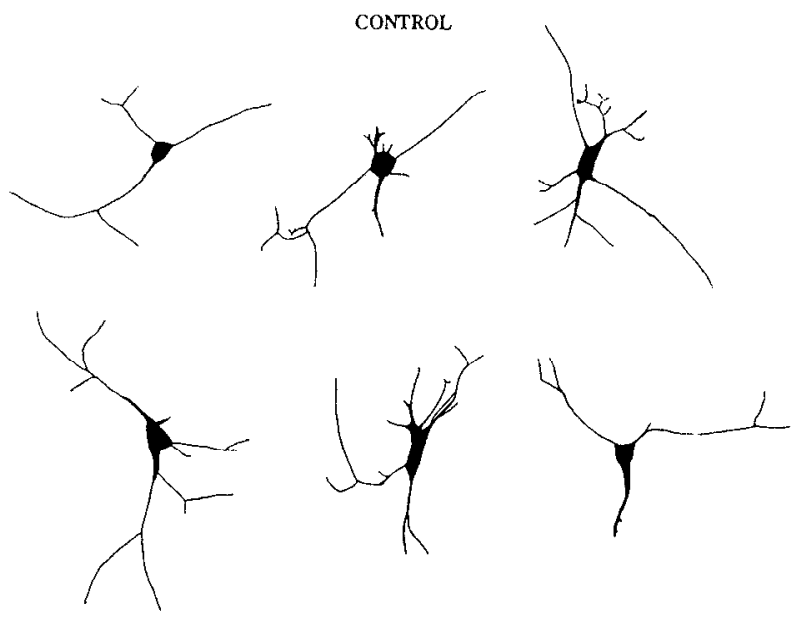

GLUTAMATE

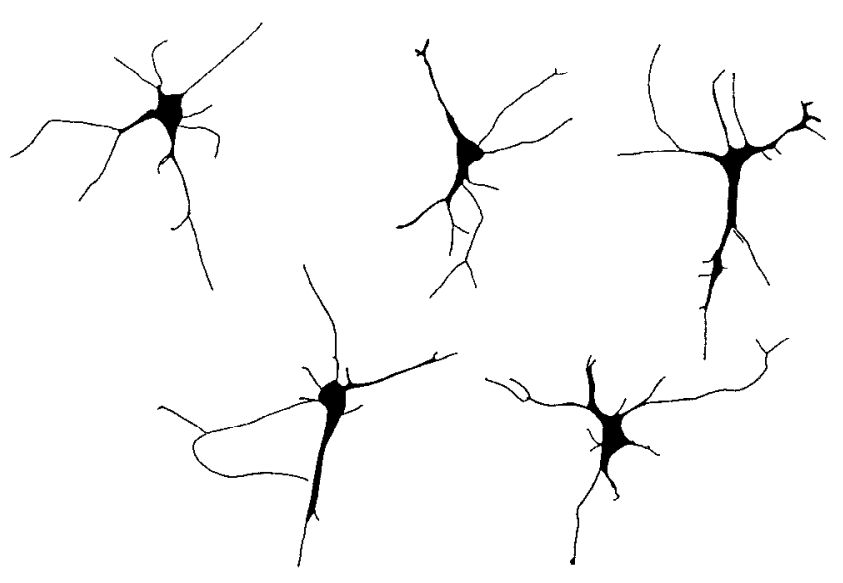

GLUTAMATE + NGF
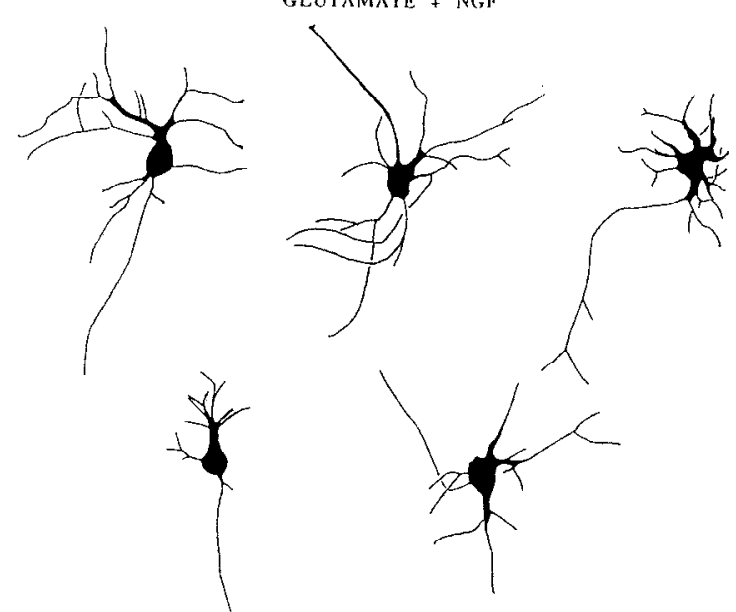

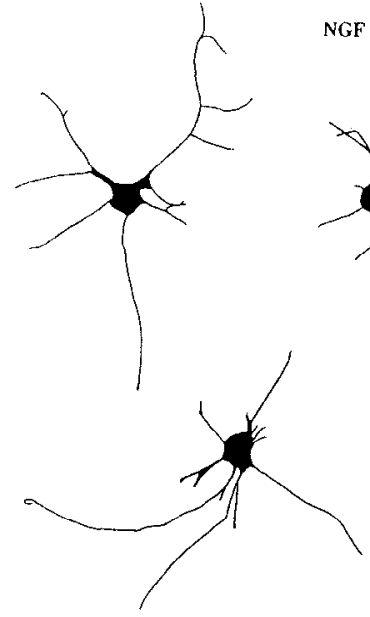

NGF
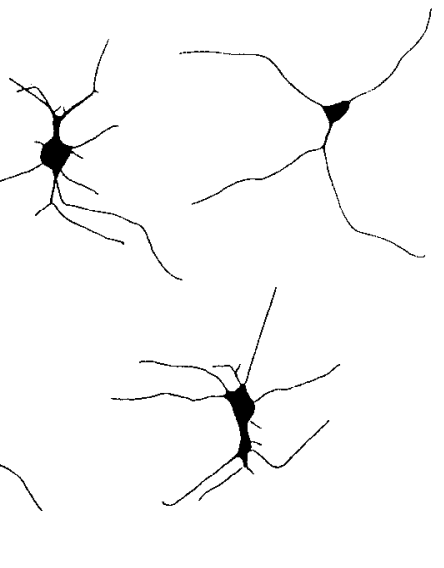

ASPARTATE
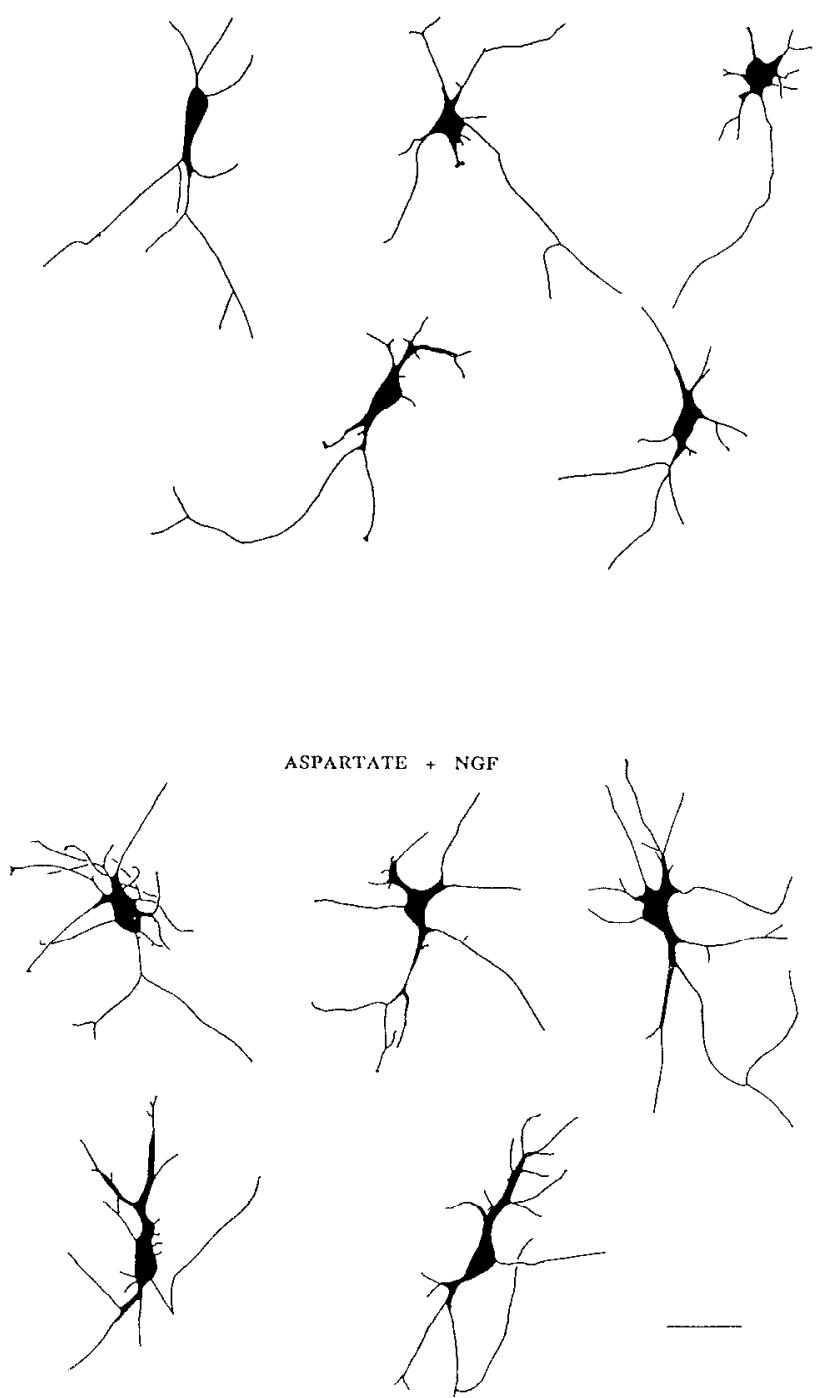

Figure 9. Morphological maturation of Purkinje cells elicited by excitatory neurotransmitters and/or NGF. Camera lucida tracings of representative CaBP-positive cells were obtained from each experimental condition. Note the marked enhancement in neurite elaboration and in cell size after treatment with glutamate with NGF, or aspartate with NGF. L-Aspartate and L-glutamate were used at $10 \mu \mathrm{M}$ final concentration, and NGF was used at $200 \mathrm{U} / \mathrm{ml}$. Scale bar, $40 \mu \mathrm{m}$. 
in concert to induce differentiation. The morphological features exhibited by these neurons in culture are similar to the features of Purkinje cells developing in vivo (Altman, 1972; Berry and Bradley, 1976a; Morris et al., 1985).

Regulation of neurite elaboration by NGF in combination with aspartate, the putative climbing fiber transmitter, or with glutamate, the putative parallel fiber transmitter, suggests that afferent stimulation and $\mathrm{NGF}$ interact to regulate dendritic development in vivo. Consequently, the temporal appearance of the 2 afferent signal catcgories may fine tune the regulation of dendritic arborization.

\section{A potential mechanism for the interaction of depolarizing signals and trophic influences}

During development, individual neurons are exposed to many environmental signals that eventually determine cell fate. Interactions among signals, and appropriate temporospatial expression, may regulate normal, orderly neuronal development and function. The idea that neural activity modulates trophic interactions during development has gained considerable attention over the last few years (for review, see Purves, 1988). A number of models based on evidence from both the PNS and CNS suggest that trophic support may be regulated by neural activity. One possible mechanism of interaction between excitatory amino acids and trophic agents has recently been proposed for the development of hippocampal ncurons in culturc (Mattson et al., 1989).

The apparent interaction of neurotransmitter and trophic agents in the regulation of neuron development may potentially be attributable to multiple mechanisms. Our recent studies, in fact, suggest a novel mode of interaction. Preliminary work from our group indicates that depolarizing influences increase receptor expression by Purkinje cells in culture (S. Cohen-Cory, R. C. Elliot, C. F. Dreyfus, and I. B. Black, unpublished observations). This raises the possibility that presynaptic stimulation in vivo may foster responsivity to $\mathrm{NGF}$, a contention we are now actively investigating.

\section{References}

Allendoerfer KL, Shelton DR, Shooter EM, Shatz CJ (1990) Nerve growth factor receptor immunoreactivity is transiently associated with the subplate neurons of the mammalian cerebral cortex. Proc Natl Acad Sci USA 87:187-190.

Altman J (1972) Postnatal development of the cerebellar cortex of the rat. II. Phases in the maturation of the Purkinje cells and of the molecular layer. J Comp Neurol 145:399-464.

Altman J, Bayer SA (1985) Embryonic development of the rat cerebellum. III. Regional differences in time of origin, migration and settling of Purkinje cells. J Comp Neurol 231:42-65.

Bernd P, Martinez HJ, Dreyfus CF, Black IB (1988) Localization of high-affinity and low-affinity nerve growth factor receptors in cultured basal forebrain. Neuroscience 26:121-129.

Berry M, Bradley $P$ (1976a) The growth of the dendritic trees in the cerebellum of the rat. Brain Res 112:1-35.

Berry M, Bradley P (1976b) The growth of the dendritic trees of Purkinje cells in irradiated agranular cerebellar cortex. Brain Res 116: 361-387.

Black IB (1978) Regulation of autonomic development. Annu Rev Neurosci 1:182-214.

Bradley P, Berry M (1976a) The effects of reduced climbing and parallel fibre input on Purkinje cell dendritic growth. Brain Res 109:133151.

Bradley P, Berry M (1976b) Quantitative effects of climbing fibre deafferentiation in the adult Purkinje cell dendritic tree. Brain Res 112:133-140.

Buck CR, Martinez HJ, Chao MV, Black IB (1988) Differential ex- pression of the nerve growth factor receptor gene in multiple brain areas. Dev Brain Res 44:259-268.

Christakos S, Rhoten WB, Feldman SC (1987) Rat calbindin D28K purification, quantitation, immunocytochemical localization and comparative aspects. In: Methods in enzymology, Vol 139' (Means AR, ed), pp 534-551. San Diego: Academic.

Cohen-Cory S, Dreyfus CF, Black IB (1989) Expression of high- and low-affinity nerve growth factor receptors by Purkinje cells in the developing rat cerebellum. Exp Neurol 105:104-109.

Crepel F, Delhaye-Bouchaud N, Dupont JL, Sotelo C (1980) Dendritic and axonal fields of Purkinje cells in developing $\mathrm{x}$-irradiated rat cerebellum. A comparative study using intracellular staining with horse radish peroxidase. Neuroscience 5:333-347.

Dreyfus CF (1989) Effects of nerve growth factor on cholinergic brain neurons. Trends Pharmacol Sci 10:145-149.

Dupont JL, Gardette R, Crepel F (1987) Postnatal development of the chemosensitivity of rat cerebellar Purkinje cells to excitatory amino acids. An in vitro study. Dev Brain Res 34:59-68.

Eckenstein F (1988) Transient expression of NGF-receptor-like immunoreactivity in postnatal rat brain and spinal cord. Brain Res 446: 149-154.

Escandon E, Chao MV (1989) Developmental expression of the chicken nerve growth factor receptor gene during brain morphogenesis. Dev Brain Res 47:187-196.

Fenton EL (1970) Tissue culture assay of nerve growth factor and the specific antiserum. Exp Cell Res 59:383-393.

Gallo V, Kingsburg A, Balazs R, Jorgensen O (1987) The role of depolarization on the survival and differentiation of cerebellar granule cells in culture. J Neurosci 7:2203-2213.

Grau-Wagemans MP, Selak I, Lefebvre PP, Moonen G (1984) Cerebellar macroneurons in serum-free cultures: evidence for intrinsic neuronotrophic and neuronotoxic activities. Dev Brain Res 15:1119.

Hatten ME (1985) Neuronal regulation of astroglial morphology and proliferation in vitro. J Cell Biol 100:384-396.

Hefti F, Dravid A, Hartikka J (1984) Chronic intraventricular injections of nerve growth factor elevate hippocampal choline acetyltransferase activity in adult rats with partial septohippocampal lesions. Brain Res 293:305-311.

Hockberger P, Tseng H, Connor JA (1987) Immunocytochemical and electrophysiological differentiation of rat cerebellar granule cells in explant cultures. J Neurosci 7:1370-1383.

Hockberger PE, Tseng HY, Connor JA (1989) Development of rat cerebellar Purkinje cells. Electrophysiological properties following acute isolation and in long term culture. J Neurosci 9:2258-2271.

Ito $M$ (1984) The cerebellum and neural control. New York: Raven.

Jande SS, Maler L, Lawson DEM (1981) Immunohistological mapping of vitamin D-dependent calcium binding protein in the brain. Nature 294:765-767.

Kingsbury A, Gallo V, Woddhams PL, Balasz R (1985) Survival, morphology and adhesion properties of cerebellar interneurones cultured in chemically defined and serum-supplemented medium. Dev Brain Res 17:17-25.

Large TH, Bodary SC, Clcgg DO, Wcskamp G, Otten U, Reichardt LF (1986) Nerve growth factor gene expression in the developing rat brain. Science 234:352-355.

Lasher J, Zagon R (1972) The effect of potassium on neuronal differentiation in culture of dissociated newborn rat cerebellum. Brain Res 7:761-770.

Lu B, Buck CR, Dreyfus CF, Black IB (1989) Expression of NGF and NGF receptor mRNA in the developing brain. Evidence for local delivery and action of NGF. Exp Neurol 104:191-199.

Martinez HJ, Dreyfus CF, Jonakait GM, Black IB (1985) Nerve growth factor promotes cholinergic development in brain striatal cultures. Proc Natl Acad Sci USA 82:7777-7781.

Mason CA, Blazeski R (1989) Climbing fibers contact target Purkinje cells in embryonic mouse cerebellum. Soc Neurosci Abstr 15:959.

Mattson MP, Murrain M, Guthric PB, Katcr SB (1989) Fibroblast growth factor and glutamate: opposing roles in the generation and degeneration of hippocampal neuroarchitecture. J Neurosci 9:37283740 .

Mobley WC, Schenker A, Shooter EM (1976) Characterization and isolation of proteolitically modified nervegrowth factor. Biochemistry 15:5543-5551.

Moran J, Patel AJ (1989) Effect of potassium depolarization on phos- 
phate activated glutaminase activity in primary cultures of cerebellar granule neurons and astroglial cells during development. Dev Brain Res 46:97-105.

Morris RJ, Beech JN, Barber PC, Raisman G (1985) Early stages of Purkinje cell maturation demonstrated by Thy-1 immunocytochemistry on postnatal rat cerebellum. J Neurocytol 14:427-452.

Nishi R, Berg DK (1981) Effects of high $\mathrm{K}^{+}$concentrations on growth and development of ciliary ganglion neurons in cell culture. Dev Biol 87:301-307.

Purves D (1988) Body and brain. A trophic theory of neural connections. Cambridge, MA: Harvard UP.

Rakic P, Sidman RL (1973) Organization of the cerebellar cortex secondary to deficit of granule cells in weaver mutant mice. J Comp Neurol 152:133-162.

Kamón y Cajal S (1911) Histologie du systeme nerveux de l'homme et des vertebres, Vol 11. Paris: Maloine.

Sadler M, Berry M (1989) Topological link-vertex analysis of the growth of Purkinje cell dendritic trees in normal, reeler, and weaver mice. J Comp Neurol 289:260-283.

Schatteman GC, Gibbs L, Lanahan AA, Claude P, Bothwell M (1988) Expression of NGF receptor in the developing and adult primate central nervous system. J Neurosci 8:860-873.
Sotelo C (1975) Anatomical physiological and biochemical studies of the cerebellum from mutant mice. II. Morphological study of cerebellar cortical neurons and circuits in the weaver mouse. Brain Res 94:19-44.

Sotelo C, Arsenio-Nunes ML (1976) Development of Purkinje cells in the absence of climbing fibers. Brain Res 111:389-395.

Thoenen H, Bandtlow C, Heumann R (1987) The physiological function of nerve growth factor in the central nervous system: comparison with the periphery. Rev Physiol Biochem Pharmacol 109:145-178.

Whittemore SR, Seiger A (1987) The expression, localization and functional significance of $\beta$-nerve growth factor in the central nervous system. Brain Res Rev 12:439-464.

Woodward DJ, Hoffer BJ, Siggins GR, Bloom FE (1971) The ontogenetic development of synaptic junctions, synaptic activation and responsiveness to neurotransmitter substances in rat cerebellar Purkinje cells. Brain Res 34:73-97.

Yan Q, Johnson EM (1988) An immunohistochemical study of the nerve growth factor (NGF) receptor in developing rats. J Neurosci 8: 3481-3498. 